\title{
Benthic foraminiferal stable carbon isotope constraints on deglacial ocean circulation and carbon-cycle changes
}

\author{
Carlye D. Peterson', G. Gebbie², L.E. Lisiecki³ , J. Lynch-Stieglitz , D. Oppo ${ }^{5}$, J. Muglia', J. Repschläger and A. \\ Schmittner ${ }^{8}$
}

\begin{abstract}
How does deep-ocean circulation influence atmospheric $\mathrm{CO}_{2}$ across deglacial transitions? Although biogeochemical and physical processes complicate interpretation of foraminiferal stable carbon isotope data, these complications can be addressed with expanded data compilations, multiproxy approaches, and model-data assimilation efforts.
\end{abstract}

The transition from glacial to interglacial climate involves carbon redistribution between the atmosphere, terrestrial biosphere, and ocean reservoirs. During repeated glaciations of the past 1 million years (Myr), about $100 \mathrm{ppm}$ of $\mathrm{CO}_{2}$ from the atmosphere was temporarily sequestered in the terrestrial biosphere and ocean. Although terrestrial biosphere carbon storage may have increased or decreased (see Jeltsch-Thömmes et al. 2019 and references therein) between the Last Glacial Maximum (LGM, 20,000 years (20 kyr) before present) and the preindustrial period, the vast, deep-ocean reservoir most likely controls glacial-interglacial carbon cycling and, hence, atmospheric $\mathrm{CO}_{2}$ variations. On these timescales, ocean circulation and biological productivity influence carbon distribution in the deep ocean and regulate glacial carbon sequestration and deglacial $\mathrm{CO}_{2}$ outgassing. However, the details of these ocean changes and their role in modulating deep-ocean carbon storage remain poorly understood. Compilations of global benthic stable carbon isotopes $\left(\delta^{13} \mathrm{C}\right)$ such as those synthesized by the PAGES Ocean Circulation and Carbon Cycling (OC3, pastglobalchanges.org/oc3) working group, can help decipher these processes.

\section{Ambiguity in proxy reconstructions} Past changes in ocean circulation and carbon storage have been reconstructed using the spatial distribution of stable carbon isotopes of dissolved inorganic carbon (DIC) inferred from stable carbon isotope records of benthic foraminifera Cibicides wuellerstorfi (and related genera) $\left(\delta^{13} C_{\text {cib }}\right)$. These records are influenced by numerous fractionation processes including surfaceocean thermodynamic fractionation, air-sea gas exchange, and biological productivity (see Mackensen and Schmiedl 2019). These processes set the unique $\delta^{13} \mathrm{C}$ source properties of modern North Atlantic Deep Water (NADW) and its glacial counterpart. Processes that drive the low $\delta^{13} \mathrm{C}$ signature of the deep ocean include diabatic and turbulent mixing of water masses with different carbon isotope signatures during circulation and the degradation of surface-produced organic matter (remineralization) that subsequently sinks into the deep ocean. The low end-member $\delta^{13} \mathrm{C}$ signature of modern southern-sourced waters, such as Antarctic
Bottom Water (AABW), is achieved through a combination of cold, dense waters forming under sea ice that are isolated from the atmosphere, water-mass mixing (see Talley 2013), and organic-matter remineralization during deep-water formation and transit. Quantifying different fractionation influences is one of the challenges to inferring past changes in deep-ocean circulation and carbon storage from $\delta^{13} \mathrm{C}_{\text {cib }}$ records.

One way to better constrain influences on $\delta^{13} C_{\text {cib }}$ paleorecords is to increase the spatial coverage of high-resolution, well-dated $\delta^{13} \mathrm{C}$ rib records. Even in relatively wellsampled regions such as the Atlantic Ocean, we must interpolate and extrapolate $\delta^{13} \mathrm{C}_{\text {cib }}$ values between core sites to capture spatial variations across ocean basins, which results in large uncertainties. To understand the temporal evolution of $\delta^{13} \mathrm{C}_{\text {ib }}$, we rely on time series of $\delta^{13} C_{c i b}$. High-resolution age models reduce the uncertainty in $\delta^{13} \mathrm{C}$. timeseries, but $\delta^{13} C_{\text {cib }}$ records with "high" temporal resolution (better than $3 \mathrm{kyr}$ ) are generally restricted to regions with high sedimentation rates and good carbonate preservation (e.g. the Atlantic Ocean). Thus, existing compilations are strongly dominated by regions with more favorable sedimentation regimes. Including low-resolution $\delta^{13} \mathrm{C}_{\text {cib }}$ records presents a trade-off between temporal and spatial resolution that is likely reasonable for characterizing the LGM and late Holocene time periods (Peterson et al. 2014).

Identifying locations of $\mathrm{CO}_{2}$ degassing can be challenging using $\delta^{13} \mathrm{C}_{\text {cib }}$ records because the strong air-sea exchange process "erases" the deep-ocean signature. However, independent nutrient proxies can help separate air-sea signals from recently upwelled deep waters (Lynch-Stieglitz et al. 2019). As such, multiproxy records allow us to estimate water-mass $\delta^{13} \mathrm{C}$ signatures at the time of their formation (i.e. "preformed" $\delta^{13} \mathrm{C}_{\mathrm{DIC}}$ ), as well as their origin and transit (Oppo et al. 2018). Therefore, multiproxy records combined with well-dated, high-resolution $\delta^{13} \mathrm{C}_{\text {cib }}$ records from numerous locations across the seafloor allow us to reconstruct water-mass properties and explore the ocean circulation and carbon-cycling signals.

Additionally, systematic and regional deviations between late Holocene $\delta^{13} \mathrm{C}_{\text {cib }}$ and nearby seawater $\delta^{13} C_{D I C}$ estimates are found in more than $1700 \delta^{13} \mathrm{C}$ records of varying temporal resolutions (Schmittner et al. 2017). This compilation suggests that the carbonate ion content of seawater has a small $(<15 \%)$ influence on $\delta{ }^{13} \mathrm{C}_{\text {cib }}$ records. Although

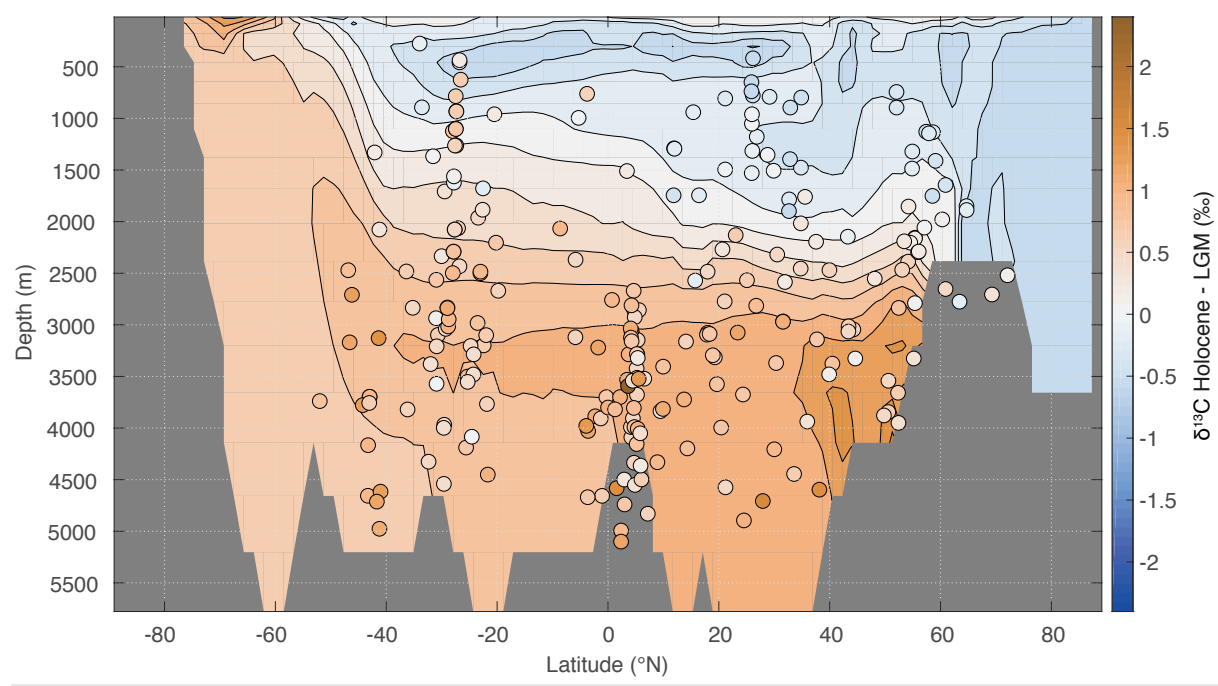

Figure 1: Observed $\delta^{13} C_{\text {cib }}$ difference between the Holocene and LGM in a zonally averaged cross section through the Atlantic Ocean integrating both the eastern and western basins (circles; $\delta^{13} \mathrm{C}$, record core sites) that constrain the model simulation of seawater $\delta^{13} C_{D I C}$ (contours) from Muglia et al. (2018). 


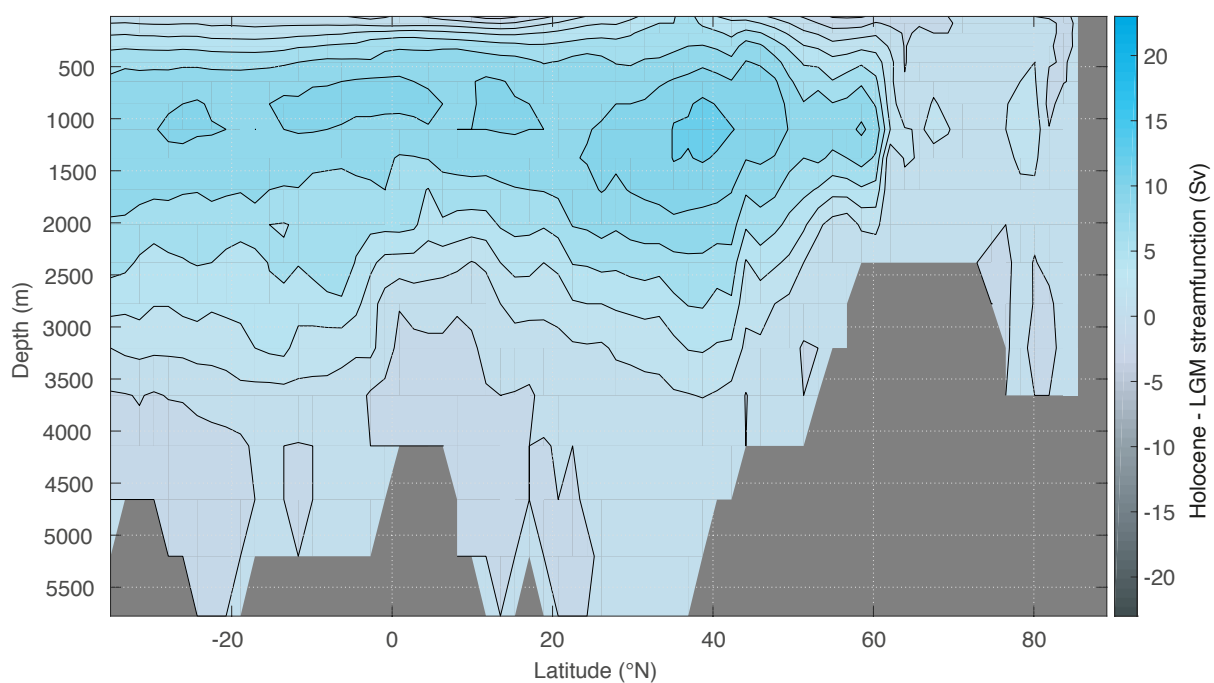

Figure 2: Zonally averaged cross section of difference in Atlantic stream function (Sv) between the Holocene and the LGM from the $\delta^{13} C_{\text {cib }}$ data-constrained numerical simulations of Muglia et al. (2018). The numerical simulations indicate that a shoaled and weaker AMOC at the LGM results in the closest match with existing datasets of seawater $\delta^{13} \mathrm{C}_{\mathrm{DIC}^{\prime}}$ i.e. $\delta^{13} \mathrm{C}_{\text {cib }}$ (Fig. 1).

$\delta^{13} \mathrm{C}_{\text {cib }}$ and $\delta^{13} \mathrm{C}_{\mathrm{DIC}}$ lack a perfect one-to-one relationship, previous $\delta{ }^{13} C_{\text {cib }}$ interpretations likely hold (Schmittner et al. 2017). The effect of deep-ocean carbonate ion variations on glacial-interglacial $\delta^{13} \mathrm{C}_{\text {cib }}$ records remains to be evaluated.

\section{Deglacial ocean circulation changes}

Classical interpretations of glacial Atlantic Ocean $\delta^{13} \mathrm{C}_{\text {cib }}$ records propose a shoaled boundary between northern-sourced NADW and southern-sourced AABW at $2000 \mathrm{~m}$ water depth (Curry and Oppo 2005). This interpretation has since been tested with additional $\delta^{13} \mathrm{C}_{\text {cib }}$ records, with an expanded spatial distribution, and new model-data comparisons (e.g. Hesse et al. 2011). Recently, Oppo et al. (2018) argued that western North Atlantic waters shoaled by about $500 \mathrm{~m}$ during the glacial onset, consistent with the prevailing hypotheses that NADW shoaled while AABW expanded (Curry and Oppo 2005). However, it remains challenging to constrain ocean circulation changes in water-mass formation regions principally because the locations of deep-water formation shifted over time. Furthermore, changes in the source properties of water masses could explain changes previously attributed to carbon and nutrient storage change (Repschläger et al. 2015).

Modeling studies constrained by glacial-age $\delta^{13} \mathrm{C}_{\text {cib }}$ records indicate a shallow and weak Atlantic Meridional Overturning Circulation (AMOC) and enhanced Southern Ocean iron fertilization (Menviel et al. 2016; Muglia et al. 2018), although it remains to be determined how well $\delta^{13} C_{\text {cib }}$ spatial variability constrains changes in AMOC strength versus depth. Additionally, model results indicate enhanced glacial Antarctic Intermediate Water (AAIW) formation in the Southern Hemisphere and a more closed circulation between NADW and AAIW (e.g. Ferrari et al. 2014). In the Atlantic Ocean, zonally averaged profiles of the difference between Holocene and LGM model-simulated seawater $\delta^{13} C_{D I C}$ and the $\delta^{13} C_{\text {cib }}$ records used to constrain the model indicate a reduced deglacial vertical $\delta^{13} \mathrm{C}_{\text {cib }}$ gradient coinciding with reduced deep-ocean carbon storage in the same model runs (Fig. 1; Muglia et al. 2018). This is in agreement with results from fewer but higher-resolution deglacial $\delta^{13} C_{\text {cib }}$ timeseries (Peterson and Lisiecki 2018). Complementary to this model run that best fits the $\delta^{13} C_{\text {cib }}$ records (Fig. 1), the zonally averaged Atlantic stream function (Sverdrup, Sv) difference between the Holocene and LGM time periods indicates a deglacial strengthening of $\mathrm{AMOC}$ at intermediate depths (surface to $1000 \mathrm{~m}$ ) throughout the Atlantic Ocean (Fig. 2).

Two deglacial depth transects of $\delta^{13} \mathrm{C}_{\text {cib }}$ records from the Southwest Atlantic and Pacific oceans suggest that the depth of glacial NADW was shallower than the sill depth of the Drake Passage (approximately $2500 \mathrm{~m}$ ), reducing the contribution of NADW to AABW formation (Sikes et al. 2017). Hence, glacial AABW may have been derived from Pacific Deep Water and Indian Deep Water (Sikes et al. 2017). Expanded abyssal AABW may have resulted from expanded sea ice (Ferrari et al. 2014), reduced basal melting of ice shelves (Miller et al. 2012) or reduced southward meridional water-vapor transport (Muglia et al. 2018). A strong LGM $\delta^{13} C_{c i b}$ gradient in the southeastern Atlantic, associated with the lowest $\delta^{13} C_{\text {cib }}$ values in the glacial ocean, may indicate a more isolated version of Circumpolar Deep Water (CDW) distinct from the CDW that filled the Pacific and Indian oceans (Ullermann et al. 2016; Williams et al. 2019).

\section{Conclusion}

For more than 50 years, paleoceanographers have sought to characterize the link between deep-ocean circulation and $\mathrm{CO}_{2}$ cycling. To gain a better understanding of these processes, the traditional interpretation of $\delta^{13} C_{\text {cib }}$ records should be re-evaluated and updated as we expand our understanding of the climate system and global carbon cycle. Collegial and interdisciplinary collaboration can foster new ideas and insights into the comparison between paleorecords and modeling approaches. By archiving our hard-earned, high-resolution multiproxy paleorecords, densely sampled age models, and model simulations in public databases online, we can improve reconstructions of ocean circulation and carbon-cycle changes based upon more complete paleodata compilations. Certainly, interpretations would benefit from improved age models and additional paleorecords from the Southern, Indian, and Pacific oceans. Together, we can synthesize our work to improve our understanding of carbon-cycle dynamics between global reservoirs and within the ocean, as well as changes in biological, physical, and chemical processes, for the past, present, and future. Community collaboration could help us extract more clues about the deglacial carbon cycle from the data we have already generated.

\section{AFFILIATIONS}

'Department of Earth Sciences, University of California Riverside, USA

2Department of Physical Oceanography, Woods Hole Oceanographic Institution, MA, USA

${ }^{3}$ Department of Earth Science, University of California Santa Barbara, USA

${ }^{4}$ School of Earth and Atmospheric Sciences, Georgia Institute of Technology, Atlanta, USA

${ }^{5}$ Department of Geology and Geophysics, Woods Hole Oceanographic Institution, MA, USA

${ }^{6}$ Center for the Study of Marine Systems (CESIMAR), Centro Nacional Patagónico, National Scientific and Technical Research Council (CONICET), Puerto Madryn, Argentina

${ }^{7}$ Max Planck Institute for Chemistry, Mainz, Germany ${ }^{8}$ College of Earth, Ocean and Atmospheric Sciences, Oregon State University, Corvallis, USA

\section{CONTACT}

Carlye Peterson: carlye.peterson@gmail.com

REFERENCES Curry WB, Oppo DW (2005) Paleoceanography 20:
PA1017

Ferrari R et al. (2014) P Natl Acad Sci 111 8753-8758 Hesse T et al. (2011) Paleoceanography 26: PA3220 Jeltsch-Thömmes A et al. (2019) Clim Past 15: 849-879 Lynch-Stieglitz J et al. (2019) Earth Planet Sc Lett 506 : 466-475

Mackensen A, Schmiedl G (2019) Earth-Sci Rev 197: 102893

Menviel L et al. (2016) Paleoceanography 32: 2-17 Miller MD et al. (2012) Paleoceanography 27: PA3207

Muglia J et al. (2018) Earth Planet Sc Lett 496: 47-56

Oppo DW et al. (2018) Paleoceanogr Paleocl 33: 1013-1034

Peterson CD et al. (2014) Paleoceanography 29: 549-563 Peterson CD, Lisiecki LE (2018) Clim Past 14: 1229-1252 Repschläger J et al. (2015) Earth Planet Sc Lett 425: 256-267

Schmittner A et al. (2017) Paleoceanography 32: 512-530 Sikes EL et al. (2017) Paleoceanography 32: 1000-1017 Talley LD (2013) Oceanography 26: 80-97

Ullermann J et al. (2016) Paleoceanography 31: 639-650 Williams TJ et al. (2019) Paleoceanogr Paleocl 34: 833-852 